\title{
Use of warm carbon dioxide insufflators does not affect intra- colonic gas temperature and has no effect on polyp detection rate during colonoscopy - a randomized controlled trial
}

(1) $\odot \ominus$

\author{
Authors \\ Akash M. Patel, Jordan Green, Fahd Jowhari, Lawrence Hookey
}

Institution

Gastrointestinal Diseases Research Unit, Department of

Medicine, Queen's University, Kingston, Ontario

submitted 14.10.2016

accepted after revision 2.3.2017

Bibliography

DOI https://doi.org/10.1055/s-0043-107779 |

Endoscopy International Open 2017; 05: E683-E689

(c) Georg Thieme Verlag KG Stuttgart · New York

ISSN 2364-3722

Corresponding author

Lawrence Hookey, Division of Gastroenterology, Hotel Dieu Hospital, 166 Brock Street, Kingston, Ontario, Canada,

K7L 5G2, +613 544 3400, ext 2292

Fax: +6145443114

hookeyl@hdh.kari.net

\section{ABSTRACT}

Background and study aims Methods to improve polyp detection during colonoscopy have been investigated, with conflicting results for warm water irrigation. Carbon Dioxide $\left(\mathrm{CO}_{2}\right)$ warmed to $37^{\circ} \mathrm{C}$ may have similar or more pro- nounced effects on bowel motility. This study aimed to assess whether warmed $\mathrm{CO}_{2}$ would improve polyp detection compared to room temperature air insufflation.

Patients and methods This was a double-blind, randomized controlled trial that enrolled 204 patients undergoing screening or surveillance outpatient colonoscopy. The primary outcome was polyp per patient detection rate. Secondary outcomes included adenoma per patient detection rates, bowel spasm, and patient comfort.

Results The trial was terminated after an interim analysis determined futility. Between the warmed $\mathrm{CO}_{2}$ and room air groups, no significant differences were found in the per-colonoscopy polyp detection rate $(P=0.57)$; overall polyp detection rate $(P=0.69)$; or adenoma detection rates $(P=$ $0.74)$. More patients in the room temperature group had lower spasm scores $(p=0.02)$; however, there was a trend towards greater patient comfort in the warmed $\mathrm{CO}_{2}$ group $(P=0.054)$. An ex-vivo study showed a significant difference between exiting $\mathrm{CO}_{2}$ temperature at the insufflator end vs. delivered $\mathrm{CO}_{2}$ temperature at the colonoscope tip end. The temperature of insufflation at the tip of the colonoscope was not different when using warmed vs. unwarmed insufflation $(P=0.62)$.

Conclusion When compared with room air insufflation, warmed $\mathrm{CO}_{2}$ insufflation did not affect polyp detection rates.

\section{Introduction}

Colorectal cancer is the second most common cancer in the world [1] and the second leading cause of cancer-related mortality [2]. Most colorectal cancers are thought to arise from precursor adenomatous polyps in a well-characterized adenoma to carcinoma sequence. Removal of such precursor lesions through screening programs reduces colorectal cancer mortality by 30 to $50 \%[3,4]$ Colonoscopy is the preferred method to detect and remove these lesions but there is a recognized miss rate of polyps, estimated to be $16 \%$ to $36 \%$, depending on the location and size of the lesion [5,6]. The majority of colorectal cancers that occur post-colonoscopy are believed to arise from lesions missed at the time of endoscopy, rather than from new lesions [7]. Endoscopists may miss polyps for several reasons including: 1) poor bowel cleansing; 2) areas of poor visualization, such as behind haustral folds; 3 ) inadequate colonoscope withdrawal times; and 4) operator fatigue [8-12].

Methods to improve detection of adenomas may help further decrease colorectal cancer mortality. Proper bowel preparation, lengthening withdrawal time, monitoring and reporting adenoma detection rates, and enhanced visualization behind haustral folds [1] have been used to increase the detection rates of colonoscopy $[8,13-16]$.

Recently, methods to reduce spasm of the colon have been investigated to increase adenoma detection rates by allowing for better inspection of colonic folds. Warm water immersion is thought to be less spasm-inducing than room temperature 
water. Compared with air insufflation, some studies have shown it to be associated with an increase in adenoma detection rates and a decrease in discomfort during colonoscopy but data to date are not convincing $[17,18]$. While water exchange has been associated with increased adenoma detection rates, the benefit seems to from a cleansing rather than motility effect [19]. Its use is limited, as it can only be used on insertion of the colonoscope, and withdrawal is the most important time for inspection of the mucosa for polyps. Thus, providing an intervention during withdrawal may be more efficacious. The antispasmodic agent hyoscine butylbromide has also been investigated as a method to increase adenoma detection rates, but again, data to date has been contradictory [20-22]. Furthermore, all of these studies have used room temperature air as the means to distend the bowel. An alternative to room temperature air insufflation is carbon dioxide $\left(\mathrm{CO}_{2}\right)$ insufflation, which has been shown to decrease post procedure bloating and pain but has not been shown to have an effect on detection rates $[23,24]$. Its safety is well demonstrated in the endoscopy setting and there is negligible risk of hypercapnia $[25,26]$.

Carbon dioxide warmed to $37^{\circ} \mathrm{C}$ may have similar or more pronounced effects on bowel motility as warm water or antispasmodic agents. Recently, an insufflator was developed to warm the $\mathrm{CO}_{2}$ (EndoStratus $\mathrm{CO}_{2}$ Insufflator, Medivators Inc., Minneapolis, MN). Its advantages include the lack of a need for special preparation of the equipment beyond usual care; no additional medications required during the procedure; no additional training or change in technique required for endoscopists; the potential for beneficial effect on both insertion and withdrawal of the colonoscope, and minimal systemic adverse effects. This study was undertaken to determine whether the use of this device would effect polyp detection during routine screening and surveillance colonoscopy.

We hypothesized that in outpatients undergoing screening colonoscopy, warmed $\mathrm{CO}_{2}$ insufflation would detect more polyps per colonoscopy compared to room temperature air insufflation.

\section{Patients and methods}

Patients undergoing screening or surveillance colonoscopies were invited to participate. A letter of invitation was mailed to them and the study discussed with a clinical research assistant upon their arrival to the endoscopy unit. If they agreed to participate, informed consent was obtained. Exclusion criteria included: previous colonic resections, active inflammatory bowel disease, hereditary polyposis syndromes, moderate to severe COPD, obstructive sleep apnea requiring CPAP or BIPAP, or neurologic diagnoses affecting ventilation.

Randomization occurred just before the patient was brought into the endoscopy room and prior to commencement of the colonoscopy. Patients were randomized to either room air insufflation or warmed $\mathrm{CO}_{2}$ in permuted blocks of 6,8 , or 10 via www.randomize.net; a secure internet-based randomization service (Interrand Inc., Ottawa, Ontario, Canada). The endoscopist and nurse then left the endoscopy room and the research assistant turned on the appropriate insufflation and en- sured concealment. The endoscopist, nurse and patient were blinded to the study assignment. The $\mathrm{CO}_{2}$ insufflator was covered with a wooden box, with the tubing outlets covered with foam to ensure there was no light leakage from the box. The pump section on the endoscopy processor was also covered to ensure blinding. At the end of the colonoscopy, the research assistant turned off the appropriate insufflator without un-blinding the endoscopy team.

All colonoscopies were performed with an adult colonoscope (Olympus CF-H180DL or Pentax EC-3890Li) by one of 10 staff gastroenterologists. Each endoscopist had extensive experience (>1000 colonoscopies performed) and polyp detection rates $>45 \%$, which correlates to adenoma detection rates of at least $25-30 \%$. Conscious sedation was administered with intravenous Midazolam and Fentanyl. The use of Hyoscine butylbromide was at the discretion of the endoscopist. If the endoscopist decided to use a pediatric colonoscope the study was terminated, as another endoscopy tower had to be used. Patients were also excluded if cecal intubation was not achieved.

Pre-procedure data collection included demographic information, indications for colonoscopy, and colon cleansing preparation type and timing (split or traditional evening before). The duration of colonoscopy, patient comfort (measured by the Nurse Administered Patient Comfort Score assessed throughout the colonoscopy), bowel preparation quality (measured by the Aronchick Scale), and the amount and type of sedation used was recorded [27]. A bowel motility scale was introduced after 45 patients were enrolled. The 5 point scale graded the appearance of the colon during the majority of time on withdrawal of the endoscope, with 1 representing an easily distended bowel and 5 representing an actively motile bowel in regular spasm, which added significant time to the exam [28].

Polyps were assessed on withdrawal of the colonoscope in the majority of cases. When a polyp was visualized, its location was noted and size was estimated using an adult biopsy forceps (Radial Jaw 4 biopsy forceps, Boston Scientific, Massachusetts, United States). A photo was taken for later calibration. Polyps were classified by size: $<6 \mathrm{~mm}, 6-9 \mathrm{~mm}$, and $>9 \mathrm{~mm}[29,30]$ Technique for polyp removal was at the discretion of the endoscopist. Histology of each polyp was recorded once available, with advanced polyps defined as tubulovillous, and/or serrated adenoma, high-grade dysplasia morphology, or adenocarcinoma [29].

\section{Ex vivo study}

An ex-vivo study was performed investigating the temperature of carbon dioxide delivered from three commercially available insufflators [Olympus $\mathrm{CO}_{2}$ Regulation Unit UCR (Olympus Canada Inc., Richmond Hill, Ontario, Canada), Medivators EndoStratus EGA-501 (Medivators Inc., Minneapolis, MN), and EZEM$\mathrm{CO}_{2}$ efficient (Bracco Diagnostics Inc., Monroe Township, NJ)]. Using two adult colonoscopes (Olympus CF-H180DL and Pentax EC-3890Li) with their lights on, the air button was continuously depressed. Temperatures were recorded at both the insufflator end and distal colonoscope end for 10 minutes, in in- 
crements of 1 minute. Ten minutes was chosen to replicate an average cecal intubation time. For each colonoscope and insufflator, experiments were performed both at room temperature and with the body of the colonoscope immersed in a warm water bath, maintained at $34^{\circ} \mathrm{C}$, to replicate the colonoscope inside the colon.

\section{Outcomes}

The primary outcome was the polyp per colonoscopy detection rate (total polyps divided by number procedures). Secondary outcomes included adenoma per colonoscopy detection rate (total number of adenomas divided by number of colonoscopies). Overall adenoma detection rate, polyp detection rate, and advanced lesion detection rate were also calculated. Bowel motility was assessed with a 5-point bowel spasm scale, adapted from previous studies [28]. Other secondary outcomes included the withdrawal time, sedation type and dose, quality of bowel preparation via the Aronchick Scale, and patient comfort by the validated Nurse-assessed Patient Comfort Score (NAPCOMS) [27, 31].

\section{Statistics}

The study was designed as a superiority study and powered to detect a $50 \%$ increase in polyp per colonoscopy detection rate with warmed $\mathrm{CO}_{2}$ insufflation compared to room air insufflation. The polyp per colonoscopy detection rate was assumed to be 0.8 and the standard deviation 1.20 [21]. A $50 \%$ increase in per colonoscopy polyp detection rates was judged to be clinically significant (i.e. 1.2 polyps per colonoscopy detection rate), partially due to the investment needed to change to warm $\mathrm{CO}_{2}$ insufflators. With an alpha set to $5 \% 1$-sided and beta $20 \%$, the number of patients required was 222 per arm. Continuous variable outcomes with normal distribution were assessed by student t-tests. Non-normally distributed ordinal variables were assessed by Mann-Whitney $U$ test and categorical data with the Chi square or Fisher's exact test.

An interim analysis was performed after 220 patients were recruited. This preliminary analysis was initially performed using only the bowel motility scale, to assess the proof of concept that warm carbon dioxide is associated with decreased spasm in order to support a grant application. When these results were reviewed however, an analysis of the primary outcome was undertaken and the study was terminated early due to futility.

The primary outcome was the average number of polyps detected per colonoscopy. We performed a futility analysis using the method of stochastic curtailment, which estimates the probability of achieving a statistically significant result at the end of the study in favour of the warmed $\mathrm{CO}_{2}$, conditional on the results observed at that point in the trial. Based on interim analysis of the 202 patients, we re-estimated the standard deviation to 2.5. Thus, the difference in the average number of polyps per colonoscopy was 0.15 in favour of warmed $\mathrm{CO}_{2}$. If we assumed that the true difference between the two arms was 0.4 , as in the original study design, then the probability of achieving a statistically significant result in favour of warmed $\mathrm{CO}_{2}$ by the end of the study was $15 \%$. If the true difference was actually only 0.15 , as was observed, then the probability of achieving a statistically significant result in favour of warmed $\mathrm{CO}_{2}$ was only $5 \%$. This, combined with new information regarding the actual temperature of the $\mathrm{CO}_{2}$ delivered at the colonoscope tip, led to early termination of the study.

For the technical study of insufflator temperatures, the temperatures were analyzed as warmed $\mathrm{CO}_{2}$ (Medivators with warmer on) versus controls (Olympus, Bracco and Medivators with warming option off) using ANOVA.

This trial was approved by the Queen's University Health Sciences Research Ethics Board and registered in an international trial registry (NCT02065037).

\section{Results}

The trial was terminated after 229 patients were enrolled and 204 completed the exams (room air $n=106$, warm $\mathrm{CO}_{2} \mathrm{n}=98$ ), between June 2014 and September 2015. Twenty five patients were not included after randomization due to incomplete colonoscopies due to poor preparation $(n=4)$, technical reasons, such as patient discomfort or looping that required switching to a pediatric colonoscope $(n=14)$, or logistic issues related to the research room availability or $\mathrm{CO}_{2}$ sources $(\mathrm{n}=7)(\triangleright \mathbf{F i g} \mathbf{1})$.

No significant differences were seen in age, gender, indication for the procedure, or bowel preparation ( $\triangleright$ Table 1 ). The NAPCOMS pain scores were however, lower in the warmed $\mathrm{CO}_{2}$ group $(p=0.05)$. Bowel cleansing scores were similar between groups, with $77.4 \%$ (room air) and $77.6 \%$ (warmed $\mathrm{CO}_{2}$ ) having good or excellent preparations $(P=0.95)$. The bowel spasm scale was significantly different between groups, with more cases in the room temperature group having scores of 1 or 2 (65\%) compared to the warm $\mathrm{CO}_{2}$ group (52.5\%) $(P=0.008)$ ( Fig. 2).

The average number of polyps per colonoscopy in the warmed $\mathrm{CO}_{2}$ group was 0.15 higher than in the room temperature air arm $(95 \% \mathrm{Cl},-0.80$ to $0.51, P=0.57)$ ( $\triangleright$ Table 2). Polyps were identified in $69 / 106$ (65\%) of the patients in the room temperature group compared to $59 / 98(60 \%)$ in the warmed $\mathrm{CO}_{2}$ group $(P=0.47)$. The adenoma detection rates were similar in both groups: $48.1 \%$ in the room air group and $45.9 \%$ in the warm $\mathrm{CO}_{2}$ group $(P=0.75)$. No differences were seen in rates of advanced adenomas or sessile serrated adenomas ( $\nabla \mathbf{T a}$ ble 2 ). The correlation between age and the number of polyps was moderate, but statistically significant $(r=0.21, P=0.003)$. There was no significant difference in the number of polyps detected according to sex $(P=0.20)$.

The ex-vivo study demonstrated that it took 5 minutes for the insufflator tip to generate a significantly higher temperature $\left(38.1^{\circ} \mathrm{C}\right)$ compared to the control insufflators $\left(23.9^{\circ} \mathrm{C}\right)$ $(P<0.001)$ ( $\vee$ Fig. 3). Despite this, there was no significant increase in temperature at the colonoscope tip end $\left(24.5^{\circ} \mathrm{C}\right.$ [warm $\mathrm{CO}_{2}$ ] vs. $23.7^{\circ}$ Celsius [control], $\left.P=0.62\right)(\triangleright$ Table 3 ). When a warm water bath was used to simulate the environment in the colon, there was still no significant difference observed in gas temperatures at the colonoscope tip end $\left(25.5^{\circ} \mathrm{C}\right.$ [warm $\mathrm{CO}_{2}$ ] vs. $23.3^{\circ} \mathrm{C}$ [control], $\left.P=0.159\right)$. There was, however, a significant difference in gas temperatures in the warm $\mathrm{CO}_{2}$ insuf- 


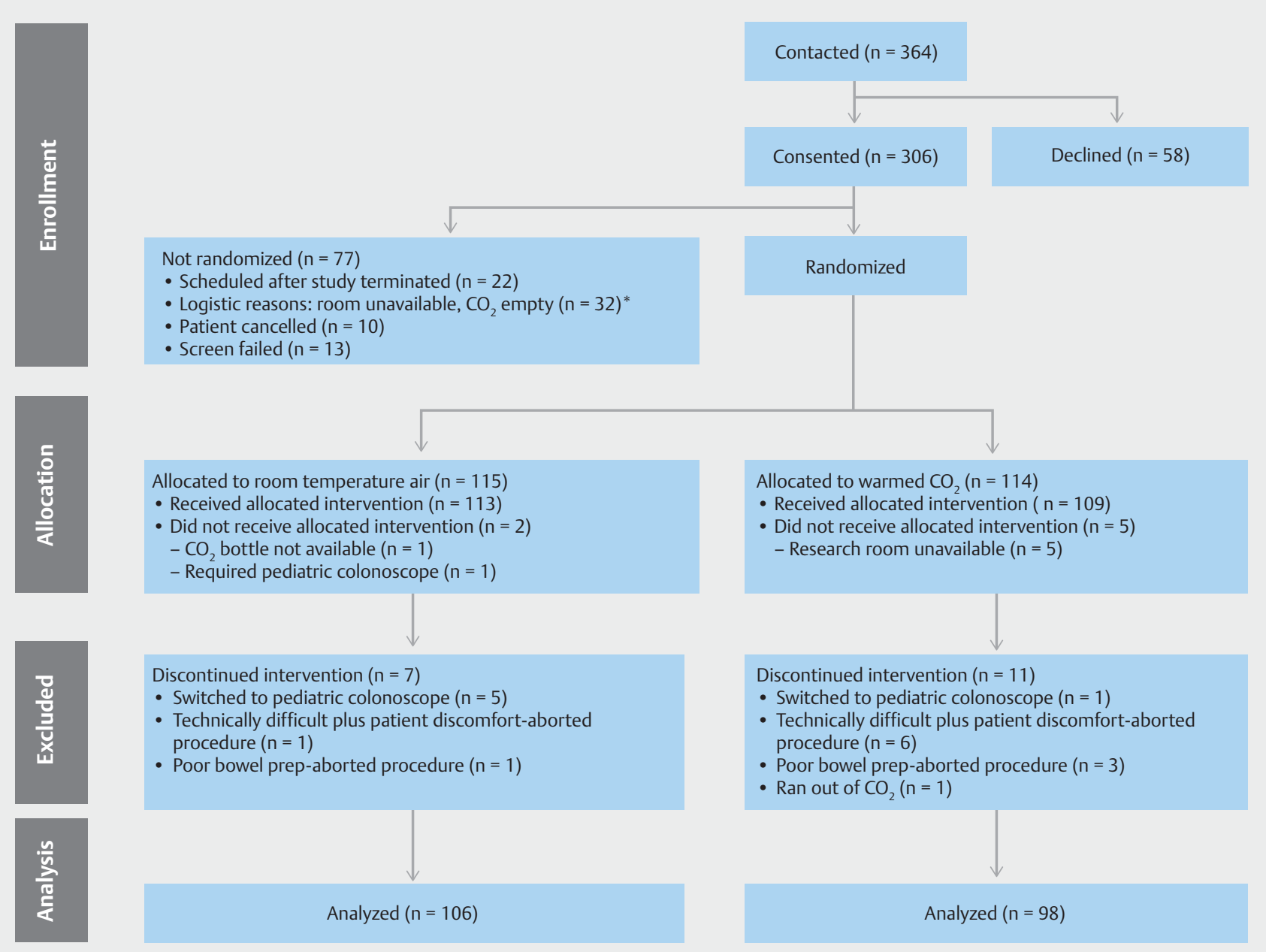

- Fig. 1 CONSORT flow diagram of subjects during study.

- Table 1 Demographics and technical details of colonoscopies.

\begin{tabular}{|c|c|c|c|c|}
\hline & & Room Air $(n=106)$ & Warmed $\mathrm{CO}_{2}(\mathrm{n}=98)$ & $P$ value \\
\hline \multicolumn{2}{|l|}{ Age (years $\pm S D$ ) } & $61.0 \pm 8.1$ & $60.6 \pm 7.6$ & 0.72 \\
\hline \multicolumn{2}{|l|}{ Gender (female) } & 52 & 51 & 0.67 \\
\hline \multicolumn{2}{|c|}{ Indication: Screening or Surveillance } & 106 & 98 & 1 \\
\hline \multirow[t]{2}{*}{ Preparation Type n (\%) } & Polyethylene glycol & $41(38.7)$ & $39(39.8)$ & \multirow[t]{2}{*}{0.58} \\
\hline & $\mathrm{P} / \mathrm{MC}^{1}$ & $65(61.3)$ & $59(60.2)$ & \\
\hline \multicolumn{2}{|c|}{ Preparation quality: \% rated excellent or good using the Aronchick Scale } & 77.4 & 77.6 & 0.66 \\
\hline \multicolumn{2}{|c|}{ Hyoscine butylbromide used (n cases) } & 11 & 13 & 0.33 \\
\hline \multicolumn{2}{|c|}{ Midazolam (mean dose in $\mathrm{mg} \pm \mathrm{SD}$ ) } & $1.6 \pm 0.6$ & $1.4 \pm 0.5$ & 0.08 \\
\hline \multicolumn{2}{|c|}{ Fentanyl (mean dose in $\mathrm{mcg} \pm \mathrm{SD}$ ) } & $75.3 \pm 28.4$ & $73.5 \pm 24.3$ & 0.63 \\
\hline \multicolumn{2}{|c|}{ Cecal intubation time (minutes \pm SD) } & $12.9 \pm 8.6$ & $11.9 \pm 6.4$ & 0.34 \\
\hline \multicolumn{2}{|c|}{ Withdrawal time (minutes \pm SD) } & $15.6 \pm 9.6$ & $16.8 \pm 8.7$ & 0.34 \\
\hline \multicolumn{2}{|l|}{ NAPCOMS pain score } & $3.1 \pm 2.2$ & $2.5 \pm 2.0$ & 0.049 \\
\hline
\end{tabular}




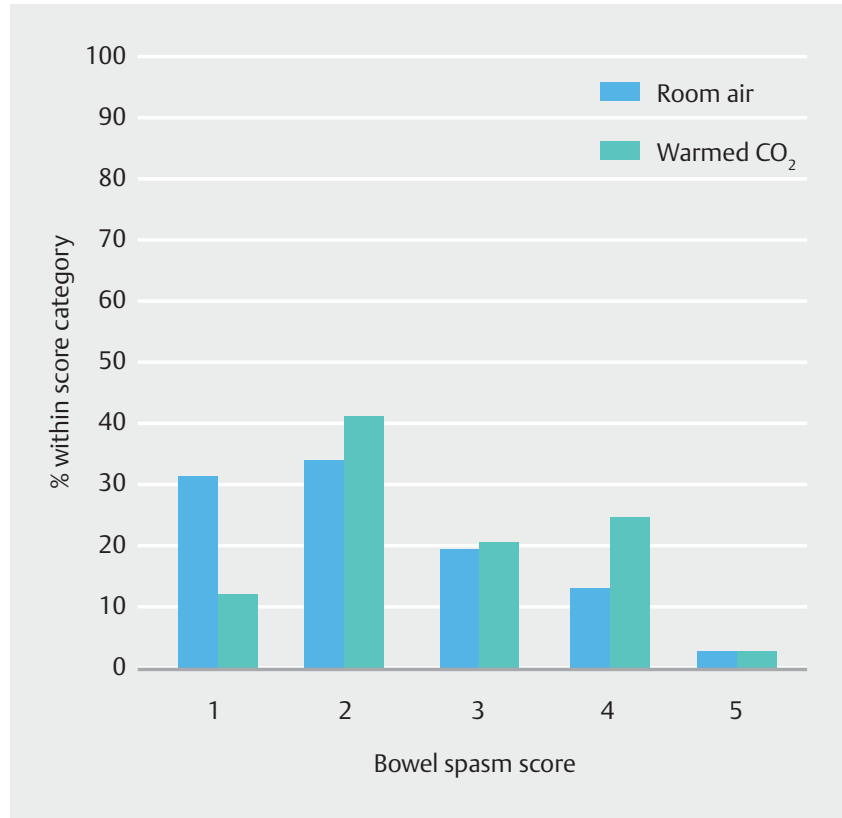

- Fig. 2 Distribution of bowel spasm scores during colonoscopy in patients in each group.

flator, between the insufflator end and colonoscope tip end, both at 5 minutes $\left(38.1^{\circ} \mathrm{C}\right.$ vs. $\left.24.2^{\circ} \mathrm{C}, P<0.001\right)$, and $10 \mathrm{~min}$ utes $\left(39.2^{\circ} \mathrm{C}\right.$ vs. $\left.24.6^{\circ} \mathrm{C}, P<0.001\right)$. This suggests that despite 10 minutes of constant warming at the insufflator end, the warm $\mathrm{CO}_{2}$ insufflator failed to deliver target temperatures to the distal tip.

\section{Discussion}

The appeal of warmed $\mathrm{CO}_{2}$ for colonoscopy is in its potential to improve polyp detection and hasten recovery for the patient. This trial is the first to investigate whether using a $\mathrm{CO}_{2}$ insufflator that warms the gas prior to it passing through the colonoscope would improve both bowel motility and polyp detection rates. Warm water immersion has been associated with improved patient comfort and adenoma detection, yet hasn't been widely adopted [17]. This is likely due to relatively major changes in endoscopist techniques required for implementa-

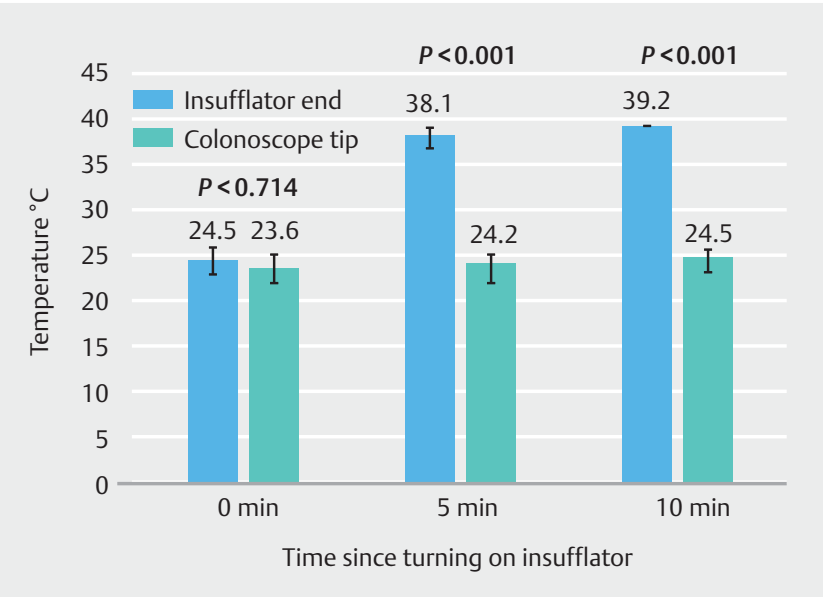

- Fig. 3 Mean temperature recordings at the insufflator tip increase over time while the air delivered to the colonoscope tip remains at a constant temperature.

tion. Hyoscine butylbromide has been shown to have effects on colonic motility and may improve polyp detection rates but the agent also has several contraindications and systemic effects, such as tachycardia and increases in ocular pressure [20-22,28]. In contrast, $\mathrm{CO}_{2}$ has no side effects or possible drug interactions, and allows for colonoscope insertion time that is the same or even less than warm water immersion [24, $32,33]$. Despite its promise, this current study failed to demonstrate a significant difference in polyp detection. Furthermore, it revealed that the $\mathrm{CO}_{2}$, while warmed at the tip of the insufflator, returns to room temperature when it leaves the colonoscope.

The approval process for such medical devices deserves review. The Endostratus $\mathrm{CO}_{2}$ Insufflator is approved for medical use in Canada, the United States, and European Union. The regulatory approvals in these regions appear to have been based on the principles of safety, or lack of harm, rather than efficacy. The data available through the regulatory agencies (Food and Drug Administration and Health Canada) suggest the manufacturer submitted data showing the insufflator warmed the gas at the point of exit of the insufflator itself, and no further data or investigations were required to see if this warming was still present at the end of the colonoscope. Nor was it necessary to

- Table2 Polyp and adenoma detection results.

\begin{tabular}{|l|c|c|}
\hline & Room Air $\mathbf{n = 1 0 6}$ & Warmed $\mathbf{C O}_{\mathbf{2}} \mathbf{n = 9 8}$ \\
\hline Polyps per colonoscopy (mean \pm SD) & $\mathbf{P}$ value \\
\hline Adenomas per colonoscopy (mean \pm SD) & $1.71 \pm 2.1$ & $1.86 \pm 2.6$ \\
\hline Polyp detection rate (\%) & $0.94 \pm 1.49$ & $1.08 \pm 1.83$ \\
\hline Adenoma detection rate (\%) & 65.1 & 60.2 \\
\hline Advanced lesion² detection rate (\%) & 48.1 & 45.9 \\
\hline $\begin{array}{l}\text { 1 Polyps per colonoscopy calculated as total number of polyps found in sample divided by number of patients in group } \\
\text { 2 Advanced lesions defined as adenocarcinoma, tubulovillous adenoma, adenoma with high grade dysplasia, or sessile serrated adenoma }\end{array}$ \\
\hline
\end{tabular}


- Table 3 Temperature measurements using the insufflator with warming option activated and controls.

\begin{tabular}{|c|c|c|c|c|c|}
\hline & & Time (minutes) & Insufflator with warmer on $(\mathrm{n}=3)\left({ }^{\circ} \mathrm{C}\right)$ & Controls $(n=7)\left({ }^{\circ} \mathrm{C}\right)$ & $P$ value \\
\hline \multirow[t]{6}{*}{ Measurement location } & \multirow[t]{3}{*}{ Insufflator tip } & 0 & 24.5 & 23.9 & 0.47 \\
\hline & & 5 & 38.1 & 23.5 & $<0.001$ \\
\hline & & 10 & 39.2 & 23.7 & $<0.001$ \\
\hline & \multirow[t]{3}{*}{ Scope tip } & 0 & 23.6 & 23.3 & 0.81 \\
\hline & & 5 & 24.2 & 23.6 & 0.72 \\
\hline & & 10 & 24.5 & 23.7 & 0.62 \\
\hline
\end{tabular}

show any clinical benefit of the change in $\mathrm{CO}_{2}$ temperature. We did request further information from the manufacturer but did not receive a response. It is worth noting however, that the manufacturer does not claim any such clinical benefit in their promotional or regulatory filing documents.

As with all trials, this study has limitations. It is a single-center trial, and is thus subject to potential bias. This is partly countered by the fact that it is a randomized, controlled, doubleblind trial, with 10 staff endoscopists. Early termination of the study deserves discussion as well. The interim analysis was performed in order to obtain preliminary data in an effort to secure funding for the trial. When no difference in favor of the warm $\mathrm{CO}_{2}$ for bowel motility was observed, we questioned the basis of the study. This lead to further investigation of the instrument itself, which unfortunately revealed that although the gas is warmed at the site of the insufflator, when it has traversed the tubing, umbilical cord of the colonoscope, and finally the shaft of the scope (a distance of approximately 4 meters), the gas returns to room temperature. This seems to happen regardless of the starting gas temperature, as seen with the other insufflator models, where room temperature $\mathrm{CO}_{2}$ arrived at the scope tip at the same temperature as the warmed $\mathrm{CO}_{2}$. Once this information was revealed, the premise of the study was lost and we deemed it unethical to continue a study of "warmed $\mathrm{CO}_{2}$ ", knowing that the $\mathrm{CO}_{2}$ was not, in fact, warmed. Past studies have already shown that room temperature $\mathrm{CO}_{2}$ has some benefits, but that increased polyp detection isn't among them. Room air was chosen as the control group, as this remains the standard of care in practice (although anecdotally it seems that $\mathrm{CO}_{2}$ use is rising), and prior studies have failed to demonstrate a benefit of room temperature $\mathrm{CO}_{2}$ compared to room air for polyp detection. It seems, however, that even if room temperature $\mathrm{CO}_{2}$ had been used in comparison to the warm $\mathrm{CO}_{2}$, the results would have been one large cohort of room temperature $\mathrm{CO}_{2}$, given the lack of practical effect of the warmer.

\section{Conclusion}

The search for methods to increase polyp detection during colonoscopy, and thus reduce colon cancer, has included many technical innovations. The current study failed to demonstrate any benefit with use of a warm $\mathrm{CO}_{2}$ insufflator, but has not truly assessed the effect of warm $\mathrm{CO}_{2}$. It is worth highlighting that as modifications and new technology are presented to us, the onus of whether such a device or innovation actually does what it is purported to do has to date been on the manufacturer. Thus, asking to review such data is a reasonable request, particularly in light of this study's results. As new technologies are introduced, a thorough examination of their premise should be undertaken. Further, it is worth remembering that one of the first major studies to change our practice yielded the simple message for endoscopists to slow down and pay attention [11]. It is likely that simple methods will continue to be the most effective, and these are the ones we should continue to seek.

\section{Acknowledgement}

Celine Morissette was instrumental in her efforts as a clinical research associate towards patient enrolment and data collection.

\section{Competing interests}

This study was supported in part by a Canadian Association of Gastroenterology Resident Research Grant. The sponsors did not have any role in study design, data collection, data analysis or manuscript preparation. Dr. Hookey has acted as a consultant for Ferring Pharmaceuticals and Cook Medical.

References

[1] Bray F, Ren JS, Masuyer E et al. Global estimates of cancer prevalence for 27 sites in the adult population in 2008. Int J Cancer 2013; 132: $1133-1145$

[2] The state of US health, 1990-2010: burden of diseases, injuries, and risk factors. JAMA 2013; 310: 591 - 608

[3] Zauber AG, Winawer S], O'Brien M] et al. Colonoscopic polypectomy and long-term prevention of colorectal-cancer deaths. N Engl J Med 2012; 366: 687-696

[4] Shaukat A, Mongin S], Geisser MS et al. Long-term mortality after screening for colorectal cancer. N Engl J Med 2013; 369: 1106-1114

[5] Heresbach D, Barrioz T, Lapalus MG et al. Miss rate for colorectal neoplastic polyps: a prospective multicenter study of back-to-back video colonoscopies. Endoscopy 2008; 40: $284-290$

[6] van Rijn JC, Reitsma JB, Stoker J et al. Polyp miss rate determined by tandem colonoscopy: a systematic review. Am J Gastroenterol 2006; 101: $343-350$ 
[7] Pohl H, Robertson DJ. Colorectal cancers detected after colonoscopy frequently result from missed lesions. Clin Gastroenterol Hepatol 2010; 8: $858-864$

[8] Lebwohl B, Kastrinos F, Glick M et al. The impact of suboptimal bowel preparation on adenoma miss rates and the factors associated with early repeat colonoscopy. Gastrointest Endosc 2011; 73: 1207-1214

[9] Kushnir VM, Oh YS, Hollander T et al. Impact of retroflexion vs. second forward view examination of the right colon on adenoma detection: a comparison study. Am J Gastroenterol 2015; 110: 415-422

[10] Chandran S, Parker F, Vaughan R et al. Right-sided adenoma detection with retroflexion versus forward-view colonoscopy. Gastrointest Endosc 2015; 81: 608-613

[11] Barclay RL, Vicari J], Doughty AS et al. Colonoscopic withdrawal times and adenoma detection during screening colonoscopy. $\mathrm{N}$ Engl J Med 2006; 355: $2533-2541$

[12] Lee CK, Cha JM, Kim WJ. Endoscopist Fatigue May Contribute to a Decline in the Effectiveness of Screening Colonoscopy. J Clin Gastroenterol 2015; 49: e51 - 56

[13] Lee TJ, Blanks RG, Rees CJ et al. Longer mean colonoscopy withdrawal time is associated with increased adenoma detection: evidence from the Bowel Cancer Screening Programme in England. Endoscopy 2013; 45: $20-26$

[14] Kaminski MF, Regula J, Kraszewska E et al. Quality indicators for colonoscopy and the risk of interval cancer. N Engl J Med 2010; 362: $1795-1803$

[15] Siersema PD, Rastogi A, Leufkens AM et al. Retrograde-viewing device improves adenoma detection rate in colonoscopies for surveillance and diagnostic workup. World J Gastroenterol 2012; 18: 3400-3408

[16] Gralnek IM. Emerging technological advancements in colonoscopy: Third Eye(R) Retroscope(R) and Third Eye(R) Panoramic(TM), Fuse(R) Full Spectrum Endoscopy(R) colonoscopy platform, Extra-Wide-Angle-View colonoscope, and NaviAid(TM) G-EYE(TM) balloon colonoscope. Dig Endosc 2015; 27: 223 -231

[17] Rabenstein T, Radaelli F, Zolk O. Warm water infusion colonoscopy: a review and meta-analysis. Endoscopy 2012; 44: 940 - 951

[18] Jun WU, Bing HU. Comparative effectiveness of water infusion vs air insufflation in colonoscopy: a meta-analysis. Colorectal Dis 2013; 15 : 404-409

[19] Cadoni S, Falt P, Sanna S et al. Impact of Colonoscopy Insertion Techniques on Adenoma Detection. Dig Dis Sci 2016; 61: 2068 - 2075

[20] Rondonotti E, Radaelli F, Paggi S et al. Hyoscine N-butylbromide for adenoma detection during colonoscopy: a randomized, double-blind, placebo-controlled study. Dig Liver Dis 2013; 45: 663-668
[21] Corte C, Dahlenburg L, Selby W et al. Hyoscine butylbromide administered at the cecum increases polyp detection: a randomized double-blind placebo-controlled trial. Endoscopy 2012; 44: 917-922

[22] de Brouwer EJ, Arbouw ME, van der Zwet WC et al. Hyoscine N-butylbromide does not improve polyp detection during colonoscopy: a double-blind, randomized, placebo-controlled, clinical trial. Gastrointest Endosc 2012; 75: 835-840

[23] $\mathrm{Wu}$ J, Hu B. The role of carbon dioxide insufflation in colonoscopy: a systematic review and meta-analysis. Endoscopy 2012; 44: 128-136

[24] Amato A, Radaelli F, Paggi S et al. Carbon dioxide insufflation or warm-water infusion versus standard air insufflation for unsedated colonoscopy: a randomized controlled trial. Dis Colon Rectum 2013; 56: $511-518$

[25] Cheng Y, Xiong XZ, Wu SJ et al. Carbon dioxide insufflation for endoscopic retrograde cholangiopancreatography: A meta-analysis and systematic review. World J Gastroenterol 2012; 18: 5622 - 5631

[26] Yamano HO, Yoshikawa K, Kimura T et al. Carbon dioxide insufflation for colonoscopy: evaluation of gas volume, abdominal pain, examination time and transcutaneous partial $\mathrm{CO} 2$ pressure. J Gastroenterol 2010; 45: 1235 - 1240

[27] Rostom A, Ross ED, Dube C et al. Development and validation of a nurse-assessed patient comfort score for colonoscopy. Gastrointest Endosc 2013; 77: 255-261

[28] Mui LM, Ng EK, Chan KC et al. Randomized, double-blinded, placebocontrolled trial of intravenously administered hyoscine N-butyl bromide in patients undergoing colonoscopy with patient-controlled sedation. Gastrointest Endosc 2004; 59: 22 - 27

[29] Lieberman DA, Rex DK, Winawer S] et al. Guidelines for colonoscopy surveillance after screening and polypectomy: a consensus update by the US Multi-Society Task Force on Colorectal Cancer. Gastroenterology 2012; 143 : $844-857$

[30] Read TE, Read JD, Butterly LF. Importance of adenomas $5 \mathrm{~mm}$ or less in diameter that are detected by sigmoidoscopy. N Engl J Med 1997; 336: $8-12$

[31] Aronchick CLW, Wright S, Dufrayne F et al. Validation of an instrument to assess colon cleansing. Am J gastro 1999; 94: 2667

[32] Cadoni S, Falt P, Gallittu P et al. Water Exchange Is the Least Painful Colonoscope Insertion Technique and Increases Completion of Unsedated Colonoscopy. Clin Gastroenterol Hepatol 2015; 13: 1972 1980e1-3

[33] Xu X, Zhu H, Chen D et al. Carbon dioxide insufflation or warm-water infusion for unsedated colonoscopy: A randomized controlled trial in patients with chronic constipation in China. Saudi J Gastroenterol 2016; $22: 18-24$ 